\title{
Comparison of the prognosis and recurrence of apparent early-stage ovarian tumors treated with laparoscopy and laparotomy: a meta-analysis of clinical studies
}

Ying Zhang ${ }^{1 \dagger}$, Shuying Fan ${ }^{2 \dagger}$, Yang Xiang ${ }^{3}$, Hua Duan ${ }^{1 *}$ and Li Sun ${ }^{4}$

\begin{abstract}
Background: This meta-analysis aimed to evaluate the prognosis and recurrence of apparent early-stage ovarian tumors treated with laparoscopy compared with laparotomy.

Methods: Clinical studies published in English were retrieved from the computerized databases Medline and Embase. A meta-analysis was performed to investigate the differences in the efficacy and safety of laparoscopy versus laparotomy in terms of postoperative complications, lengths of hospital stay, recurrence rates, and disease-free survival times using the random effects model. The studies were independently reviewed by two investigators. Data from the eligible studies were extracted, and the meta-analysis was performed using the Comprehensive Meta-Analysis program, version 2 (CMA-2; Biostat, Englewood, NJ, USA).
\end{abstract}

Results: A total of 8 studies were included in the analysis. The results showed that laparoscopic surgery was significantly associated with lower rates of complications $(\mathrm{OR}=0.433, P=0.019)$ and shorter postoperative hospital stays (weighted mean difference $[\mathrm{WMD}]=-0.974, P<0.001)$. There was no significant difference in the rates of recurrence $(\mathrm{OR}=0.707$, $P=0.521$ ) between patients with apparent early-stage ovarian tumors who were treated using laparoscopy and those who underwent laparotomy. No publication bias was detected.

Conclusions: Laparoscopic surgery shows favorable prognostic outcomes in terms of postoperative complication rates and postoperative hospital stay durations. Further studies with longer follow-up periods are required to confirm recurrence and survival outcomes after laparoscopic surgery in patients with apparent early-stage ovarian tumors.

\section{Background}

Ovarian cancer is among the major gynecological malignant tumors, and it ranks first in mortality among gynecological malignancies. Studies have shown that the 5 -year survival rate for ovarian cancer is as low as approximately $30 \%$, though these rates have markedly increased in recent decades with the development of new treatments and regimens $[1,2]$.

Ovarian cancer is difficult to identify in its early stage, and $70 \%$ of patients are diagnosed at an

\footnotetext{
*Correspondence: Iwtgslhy@126.com

${ }^{\dagger}$ Equal contributors

'Department of Gynecology Minimally Invasive Center, Beijing Obstetrics and Gynecology Hospital,Capital Medical University, \#17 Qi He Lou Street, Dongcheng District, Beijing 100006, China

Full list of author information is available at the end of the article
}

advanced stage, resulting in a poor prognosis. Indeed, the early diagnosis of ovarian cancer is crucial to improving treatment efficacy. Currently, the standard treatment for early-stage ovarian cancer is primarily surgical management (with or without chemotherapy). According to the International Federation of Gynecology and Obstetrics (FIGO) guidelines, the optimal staging procedures for ovarian cancer are complete abdominal hysterectomy, bilateral salpingo-oophorectomy, peritoneal biopsy, omentectomy, diaphragmatic scraping, bilateral pelvic and para-aortic lymph node dissection, and maximal debulking efforts to leave "no visible and no palpable disease" [3]. Clinical practice has proven that laparotomy is effective as a traditional surgical treatment for ovarian cancer $[4,5]$. In addition, the efficacy of laparoscopy, a minimally invasive procedure, has been demonstrated in 
recent years [6]. Laparoscopy offers the primary advantages of minimal trauma and rapid recovery and is currently widely used in the diagnosis and treatment of malignant gynecological tumors. Studies suggest that compared with laparotomy, laparoscopy is associated with shorter hospital stays, lower morbidity, and shorter recovery times $[7,8]$.

Nonetheless, studies examining the effects of laparoscopy versus laparotomy in treating apparent early-stage ovarian cancer have involved limited numbers of patients, and randomized controlled trials are not available. The present review systematically combines existing clinical studies that compared the effects of laparoscopy versus laparotomy in treating apparent early-stage ovarian cancer to evaluate the prognosis and recurrence of laparoscopy and reach a conclusion with high credibility. A random-effects meta-analysis following the MOOSE guidelines [9] for observational studies and the QUORUM guidelines for randomized controlled trials was utilized [10].

\section{Methods}

\section{Search strategy for identifying studies}

An in-depth literature search was performed using the keywords "laparoscopy," "ovarian tumor," "clinical study," and "early-stage" in various combinations. The computerized databases PubMed (from 1980 to May 2014) and Embase (from 1980 to May 2014) were searched to identify clinical studies in English-language journals. We also searched the related references in the retrieved studies and reviewed articles from the bibliographic database. The corresponding authors of some studies were contacted for information beyond what was available in their published articles.

\section{Article selection criteria}

All clinical studies that explored the differences in prognosis and/or recurrence of apparent early-stage ovarian tumors (stage I and stage II, according to the FIGO classification) treated with laparotomy versus laparoscopy were considered eligible for the analysis. Two investigators (Ying Zhang and Hua Duan) independently assessed the articles for relevance. Articles were excluded if (1) no comparisons were made between laparoscopy and laparotomy and (2) no standardized effect size could be calculated. This study was approved by the Institutional Review Board of the Beijing Obstetrics and Gynecology Hospital affiliated with the Capital University of Medical Sciences. All of the procedures used in this study are in compliance with the Helsinki Declaration.

\section{Statistical analyses}

Data management and analysis were performed using the Comprehensive Meta-Analysis program, version 2 (CMA-2; Biostat, Englewood, NJ, USA). The outcomes were pooled statistically using the event rates calculated for postoperative complications and recurrence rates and the standard mean difference for length of hospital stay. A random-effects meta-analysis was conducted to investigate the efficacy and safety of laparoscopy versus laparotomy to treat apparent earlystage ovarian tumors.

The measure of heterogeneity was evaluated using the Cochran Q test. Additionally, heterogeneity (measured as $\mathrm{I}^{2}$ ) was used to assess the percentage of the total variation from all studies. A high value for $\mathrm{I}^{2}$ indicates heterogeneity. Publication bias was evaluated using Egger's test.

\section{Results}

A total of 387 abstracts were initially selected through database searches, and 352 articles were excluded because they failed to meet the inclusion criteria. Of the remaining 35 articles, 8 did not have a comparison group, 6 were review articles, 3 focused on different types of laparoscopic surgery, 2 included the same data that were presented in other studies, 4 did not provide sufficient information to calculate an effect size, and 4 were case studies. The articles excluded from this study are shown in Fig. 1, and the 8 articles $[8,11-17]$ selected for our analysis are shown in Table 1.

In the 8 studies that were analyzed, the efficacy and safety of laparoscopy versus laparotomy in the treatment of apparent early-stage ovarian cancer were investigated. The pooled clinical studies that examined the prognosis and recurrence of apparent early-stage ovarian tumors treated with laparoscopy showed that compared with laparotomy, laparoscopic surgery was significantly associated with lower complication rates $(\mathrm{OR}=0.433,95 \%$ CI: 0.215 to $0.869, \mathrm{Z}=-2.353, P=0.019$; Fig. 2 ) and shorter postoperative hospital stays $(\mathrm{WMD}=-0.974, \mathrm{SE}=0.220$, $\mathrm{Z}=-4.420, P<0.001$; Fig. 3). In terms of recurrence rates, there was no significant difference $(\mathrm{OR}=0.707,95 \%$ CI: 0.245 to $2.037, \mathrm{Z}=-0.642, P=0.521$; Fig. 4) between patients with apparent early-stage ovarian tumors who were treated with laparoscopy and those who underwent laparotomy. In Liu's study (2014), the disease-free survival times were 54.3 months and 57.2 months for patients who were treated with laparoscopy and laparotomy, respectively.

There was statistically significant heterogeneity in the models for hospital stay $(\mathrm{Q}=24.055, P=0.001$, $\left.I^{2}=75.057\right)$, but no significant heterogeneity was observed in the models for the rates of complications $\left(\mathrm{Q}=7.041, P=0.317, \mathrm{I}^{2}=14.784\right)$ or recurrence $(\mathrm{Q}=6.570$, $\left.P=0.255, \mathrm{I}^{2}=23.898\right)$. Publication bias was examined using funnel plots and Egger's regression test, and both indicated that there was no significant publication 


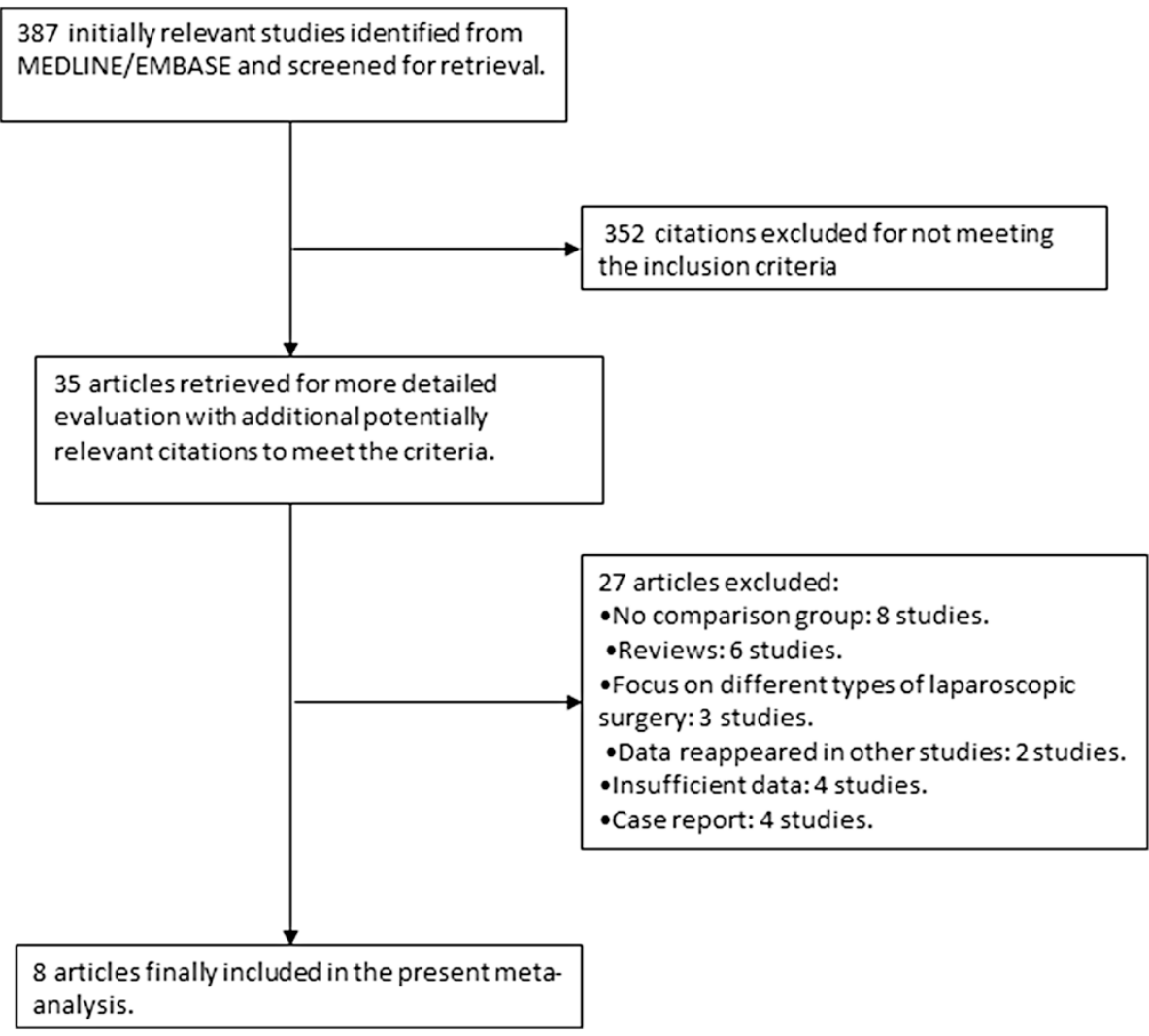

Fig. 1 Flow chart describing the article selection process

bias $(P>0.05)$ in the outcomes of this meta-analysis. Consequently, unpublished data were not further evaluated.

\section{Discussion}

In gynecologic oncology, laparoscopic surgery is considered capable of potentially providing a sufficient degree of visualization, via optical magnification, for allowing for optimal performance and accurate verification of resection, while simultaneously allowing for preservation of vital structures, such as small vessels, that may be barely visible to the naked eye [18, 19]. This study aimed to explore the effectiveness of laparoscopy versus laparotomy for the treatment of apparent early-stage ovarian tumors. The results confirmed the favorable prognostic outcomes of laparoscopy for reducing the lengths of hospital stays and the rates of postoperative complications in patients with apparent earlystage ovarian tumors. Specifically, the aggregated effect size revealed that laparoscopic surgery was significantly associated with fewer complications $(\mathrm{OR}=0.433,95 \% \mathrm{CI}$ : 0.215 to $0.869, \quad Z=-2.353, P=0.019)$ and shorter postoperative hospital stays $(\mathrm{WMD}=-0.974, \mathrm{SE}=0.220$,
$Z=-4.420, P<0.001)$. These findings are consistent with those from studies reporting the advantages of laparoscopy in treating ovarian tumors [7, 12, 20]. Lee [12] reported that complete surgical staging via laparoscopy $(n=26)$ resulted in reduced blood loss, earlier diet resumption, lower postoperative pain scores, and shorter hospital stays compared with staging via laparotomy $(n=113)$ in patients with apparent earlystage ovarian cancer. Laparoscopic surgery has been associated with less intraoperative blood loss and shorter postoperative hospital stays compared with laparotomy [17, 21]. A major concern regarding laparoscopic surgery is the risk of port-site metastasis, which has incidence rates of $1 \%-16 \%$ [13]. However, in a number of studies on apparent early-stage ovarian cancer, no cases of port-site metastasis or recurrence were reported in patients who had undergone laparoscopy [14, 22]. Additionally, the inability to utilize fine tactile assessment during laparoscopic surgery to assess the extent of disease may result in the non-recognition of occult metastatic deposits of disease that may be situated within difficult to visualize areas within the abdomen and pelvis. To compensate for this deficiency in the use of laparoscopic surgery 
Table 1 Main characteristics of the selected studies

\begin{tabular}{|c|c|c|c|c|c|c|c|c|c|c|c|c|c|c|}
\hline \multirow[t]{2}{*}{ Citation } & \multirow[t]{2}{*}{$\begin{array}{l}\text { Mean patient } \\
\text { age (years) }\end{array}$} & \multirow[t]{2}{*}{$\begin{array}{l}\text { Number of } \\
\text { patients }\end{array}$} & \multirow[t]{2}{*}{$\begin{array}{l}\text { Body mass } \\
\text { index }\end{array}$} & \multirow[t]{2}{*}{$\begin{array}{l}\text { Upstaging } \\
\text { rate }\end{array}$} & \multicolumn{2}{|l|}{$\begin{array}{l}\text { Duration of } \\
\text { operation (min) }\end{array}$} & \multicolumn{2}{|l|}{$\begin{array}{l}\text { Intraoperative } \\
\text { blood loss (ml) }\end{array}$} & \multicolumn{2}{|c|}{ Hospital stay (days) } & \multicolumn{2}{|c|}{$\begin{array}{l}\text { Number of pelvic } \\
\text { lymph node dissections }\end{array}$} & \multicolumn{2}{|c|}{$\begin{array}{l}\text { Number of para-aortic } \\
\text { lymph node dissections }\end{array}$} \\
\hline & & & & & Laparoscopy & Laparotomy & Laparoscopy & Laparotomy & Laparoscopy & $\overline{\text { Laparotomy }}$ & Laparoscopy & $\overline{\text { Laparotomy }}$ & Laparoscopy & Laparotomy \\
\hline $\begin{array}{l}\text { Liu } \\
2014\end{array}$ & 50.9 & 75 & NA & $20.0 \%$ & $209.71 \pm 17.57$ & $200.50 \pm 20.62$ & $197.14 \pm 98.48$ & $345.00 \pm 165.95$ & $16.3 \pm 6.2$ & $21.9 \pm 4.9$ & $18.23 \pm 3.27$ & $19.03 \pm 3.15$ & NA & NA \\
\hline $\begin{array}{l}\text { Koo } \\
2013\end{array}$ & 47.6 & 77 & 23.5 & $29.9 \%$ & $192.9 \pm 73.5$ & $224.1 \pm 85.4$ & $697.9 \pm 396.9$ & $972.6 \pm 827.8$ & $13.7 \pm 5.4$ & $13.1 \pm 4.1$ & $26.8 \pm 8.5$ & $27.8 \pm 13.2$ & $17.7 \pm 10.1$ & $21.2 \pm 11.2$ \\
\hline $\begin{array}{l}\text { Lee } \\
2011\end{array}$ & 43.9 & 113 & 23.0 & $26.5 \%$ & $227.6 \pm 105.8$ & $184.6 \pm 61.4$ & $230.4 \pm 183.6$ & $474.8 \pm 329.2$ & $6.4 \pm 2.6$ & $12.4 \pm 5.5$ & $23.5 \pm 9.3$ & $22.8 \pm 10.2$ & $9.9 \pm 7.4$ & $4.8 \pm 4.1$ \\
\hline $\begin{array}{l}\text { Park } \\
2008 \text { (1) }\end{array}$ & 44.9 & 52 & 22.9 & $21.2 \%$ & $220.7 \pm 82.7$ & $274.7 \pm 63.2$ & $240.0 \pm 228.3$ & $568.2 \pm 451.7$ & $8.9 \pm 6.1$ & $14.5 \pm 5.6$ & $27.2 \pm 9.7$ & $33.9 \pm 14.5$ & $6.6 \pm 6.2$ & $8.8 \pm 8.1$ \\
\hline $\begin{array}{l}\text { Park } \\
2008 \text { (2) }\end{array}$ & 46.2 & 36 & 23.5 & $19.4 \%$ & $303.8 \pm 84.9$ & $290.4 \pm 120.8$ & $231.2 \pm 117.9$ & $505.3 \pm 279.8$ & $9.4 \pm 4.1$ & $14.1 \pm 4.2$ & $13.7 \pm 5.6$ & $19.3 \pm 10.1$ & $8.9 \pm 7.1$ & $6.4 \pm 3.9$ \\
\hline $\begin{array}{l}\text { Ghezzi } \\
2007\end{array}$ & 58.4 & 34 & 24.9 & 29.45 & $377.0 \pm 47.0$ & $272.0 \pm 81.0$ & $\begin{array}{l}250.0 \\
(50-1,000)\end{array}$ & $400(150-1,000)$ & $3.0 \pm 2.5$ & $7.0 \pm 2.5$ & $25.2 \pm 9.3$ & $25.1 \pm 5.8$ & $6.5 \pm 3.9$ & $7.0 \pm 4.5$ \\
\hline $\begin{array}{l}\text { Lécuru } \\
2006\end{array}$ & 49.2 & 148 & NA & $19.0 \%$ & NA & NA & NA & NA & NA & NA & NA & NA & NA & NA \\
\hline $\begin{array}{l}\text { Chi } \\
2005\end{array}$ & 49.0 & 50 & 25.1 & NA & $321.0 \pm 64.0$ & $276.0 \pm 68.0$ & $235.0 \pm 138.0$ & $367.0 \pm 208.0$ & $3.1 \pm 0.7$ & $5.8 \pm 2.6$ & $12.3 \pm 4.9$ & $14.7 \pm 5.7$ & $6.7 \pm 2.5$ & $9.2 \pm 5.0$ \\
\hline
\end{tabular}

(1) and (2) represent different studies by the same first author 


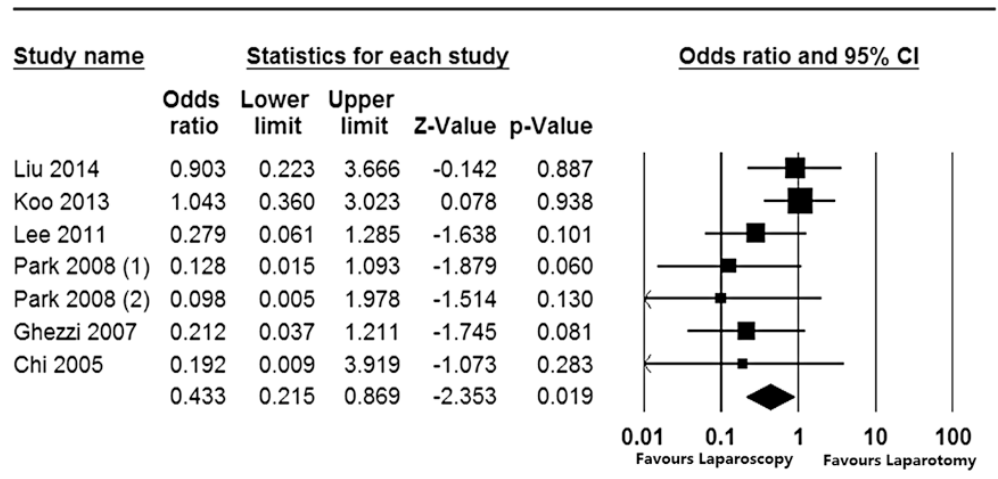

Fig. 2 Forest plot for the aggregated rate of laparoscopy-related complications in patients with apparent early-stage ovarian tumors

for staging, we suggest that preoperative examinations, such as PET-CTs, be used to detect early metastases so that they can be resected in a timely manner. Notably, it is impossible to summarize the hospital stay outcomes in this meta-analysis because of the studies' considerable heterogeneity, which could have resulted from specific differences in the patients' conditions and the study designs [20,23, 24].

In this meta-analysis, no significant difference was detected in the recurrence rates $(\mathrm{OR}=0.707,95 \% \mathrm{CI}: 0.245$ to $2.037, \mathrm{Z}=-0.642, P=0.521$ ) of patients with apparent early-stage ovarian tumors who were treated laparoscopically and those who underwent laparotomy. Koo [13] conducted a prospective study with a mean followup period of 31 months and found that tumor recurrence occurred in $2(8.3 \%)$ patients in the laparoscopy group and $2(3.8 \%)$ in the laparotomy group $(P=0.585)$. There was no significant difference in the mean disease-free survival time, which was excellent in both groups (59 months after laparoscopy versus 66 months after laparotomy, $P=0.367$ ). Studies have reported that laparoscopy decreases surgical morbidity and improves cancer-related survival times by preserving patients' cellular immunity [25-27]. In this study, the pooled disease-free survival time was not computed because the related data were only available in two of the included studies (Koo 2013 \& Lee 2011). Koo (2013) reported that laparoscopy and laparotomy were associated with disease-free survival times of $59.3 \pm$ 3.78 months and $66.3 \pm 1.92$ months, respectively. In contrast, Lee (2011) found that patients with apparent early-stage ovarian tumors who received laparoscopy or laparotomy had disease-free survival times of $13.3 \pm 10.2$ months and $25.7 \pm 15.0$ months, respectively. However, in a large series that included the laparoscopic staging of 300 patients with apparent early-stage ovarian cancers, laparoscopic surgical management exhibited excellent safety in terms of

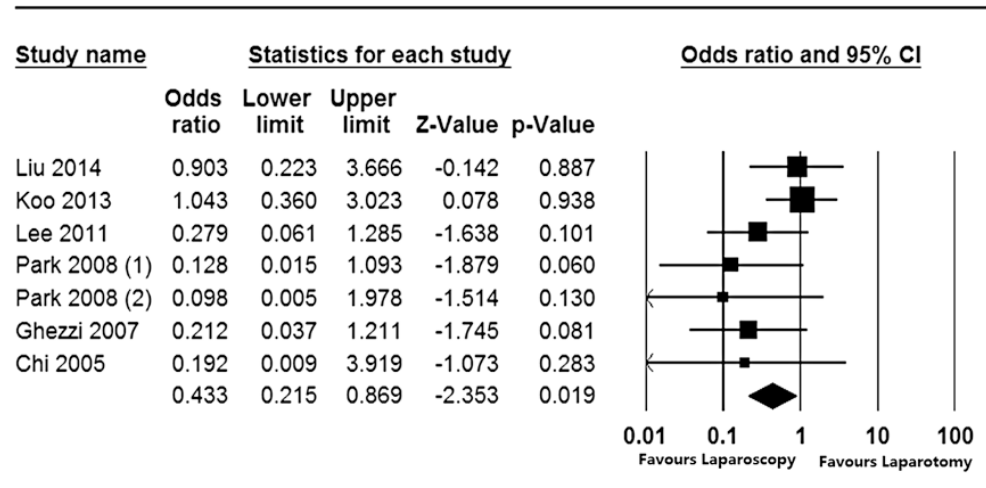

Fig. 3 Forest plot for the aggregated length of hospital stays following laparoscopy in patients with apparent early-stage ovarian tumors 


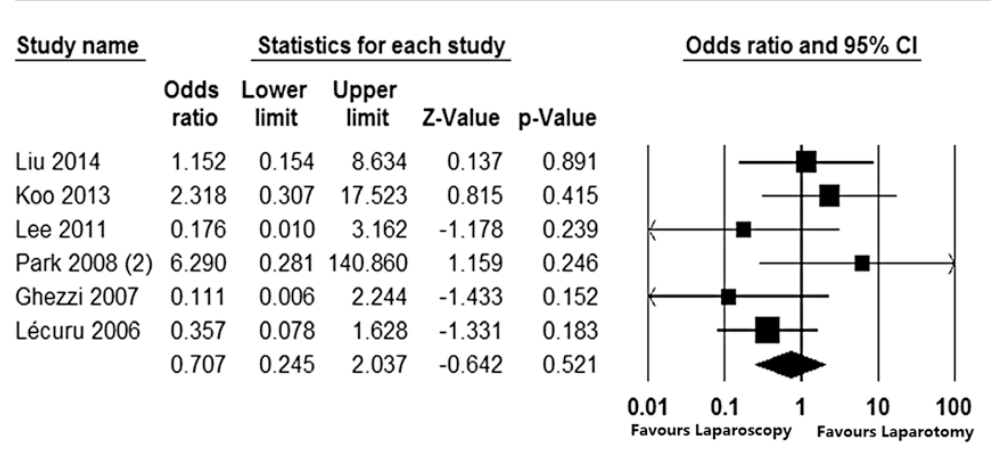

Fig. 4 Forest plot for the aggregated laparoscopy recurrence rate in patients with apparent early-stage ovarian tumors

recurrence and death from disease; 25 patients $(8.3 \%)$ underwent immediate laparoscopic staging and $10(3.3 \%)$ underwent delayed laparoscopic staging, and the 3-year disease free survival and overall survival rates were $85.1 \%$ and $93.6 \%$, respectively, for all patients [28]. Future research should include more studies with relatively longer follow-ups to investigate recurrence rates and survival outcomes.

The current review retrieved clinical studies published through May 2014 that estimated the prognostic outcomes of laparoscopic treatment for apparent early-stage ovarian tumors. The findings of our review and meta-analysis are therefore valuable for physicians and policy makers, given the benefits of laparoscopic treatment in terms of reducing hospital stays and complication rates for patients with early-stage ovarian tumors. We employed random-effects models based on the heterogeneity of the true effects distribution, which avoided the bias of overstating the precision of findings in fixed-effects models. A limitation of the current study is the small number of studies and the limited numbers of participants involved. This reflects the paucity of high-quality clinical trials that address the efficacy of laparoscopic surgery for treating ovarian tumors. Generalizations of this study's conclusions to all patients with early-stage ovarian tumors should be considered with caution, and there is still considerable need for higher quality studies with relatively larger sample sizes to address this topic.

\section{Conclusion}

In conclusion, this meta-analysis confirms that laparoscopy has favorable prognostic outcomes in terms of the postoperative complications rate and the lengths of post-operative hospital compared with conventional laparotomy in the treatment of apparent early-stage ovarian tumors. Laparoscopic surgery may be effective and feasible for treating apparent early-stage ovarian tumors.

\section{Abbreviations}

FIGO: the International Federation of Gynecology and Obstetrics; CMA-2: Comprehensive Meta-Analysis Program, version 2.

\section{Competing interests}

The authors declare that there are no conflicts of interest in relation to the current study. The authors are responsible for the writing and the content of this article.

\section{Authors' contributions}

YZ conducted the study and drafted the manuscript. SF and YX participated in the extraction and analysis of data. HD and LS conceived the study, participated in its design and coordination and helped to draft the manuscript. All of the authors read and approved the final manuscript.

\section{Acknowledgements}

Dr. Tao Wen reviewed this manuscript's design and language preparation. We greatly appreciate his support.

\section{Author details}

'Department of Gynecology Minimally Invasive Center, Beijing Obstetrics and Gynecology Hospital,Capital Medical University, \#17 Qi He Lou Street, Dongcheng District, Beijing 100006, China. ${ }^{2}$ Department of Gynecology and Obstetrics, Kailuan General Hospital, \#57 Xinhua East Road, Tangshan 063000Hebei, China. ${ }^{3}$ Department of Obsteric and Gynecology, Peking Union Medical College Hospital, Peking Union Medical College, Chinese Academy of Medical Sciences, \#1 Shuai Fu Yuanx, Dong Cheng District, Beijing 100730, China. ${ }^{4}$ Department of Medical Oncology, the Central Hospital of Xuzhou, the Cancer Institute of Southeast University, Xuzhou, Jiangsu 221009, China.

Received: 24 December 2014 Accepted: 14 August 2015 Published online: 26 August 2015

\section{References}

1. Tingulstad S, Skjeldestad FE, Halvorsen TB, Hagen B. Survival and prognostic factors in patients with ovarian cancer. Obstet Gynecol. 2003;101 (5 Pt 1):885-91.

2. Jacobs IJ, Skates SJ, MacDonald N, Menon U, Rosenthal AN, Davies AP, et al. Screening for ovarian cancer: a pilot randomised controlled trial. Lancet. 1999;353(9160):1207-10.

3. Benedet IL, Bender $\mathrm{H}$, Jones 3rd H, Ngan HY, Pecorelli S. FIGO staging classifications and clinical practice guidelines in the management of 
gynecologic cancers. FIGO Committee on Gynecologic Oncology. Int J Gynaecol Obstet. 2000;70(2):209-62.

4. Trimbos JB, Bolis G. Guidelines for surgical staging of ovarian cancer. Obstet Gynecol Surv. 1994;49(12):814-6.

5. DH M. Primary surgical management of early epithelial ovarian carcinoma. In: Rubin SC SG, editor. Ovarian cancer. 2nd ed. Philadelphia: Lippincott Williams \& Wilkins; 2001. p. 201-18.

6. Lazarov N, Lazarov L, Lazarov S. [Laparoscopy and early ovarian cancer]. Akush Ginekol (Sofiia). 2013;52(3):60-2.

7. Nezhat FR, Ezzati M, Chuang L, Shamshirsaz AA, Rahaman J, Gretz H. Laparoscopic management of early ovarian and fallopian tube cancers: surgical and survival outcome. Am J Obstet Gynecol. 2009;200(1):83. e81-86.

8. Ghezzi F, Cromi A, Uccella S, Bergamini V, Tomera S, Franchi M, et al. Laparoscopy versus laparotomy for the surgical management of apparent early stage ovarian cancer. Gynecol Oncol. 2007;105(2):409-13.

9. Stroup DF, Berlin JA, Morton SC, Olkin I, Williamson GD, Rennie D, et al. Meta-analysis of observational studies in epidemiology: a proposal for reporting. Meta-analysis Of Observational Studies in Epidemiology (MOOSE) group. Jama. 2000;283(15):2008-12.

10. Moher D, Cook DJ, Eastwood S, Olkin I, Rennie D, Stroup DF. Improving the quality of reports of meta-analyses of randomised controlled trials: the QUOROM statement. Quality of Reporting of Meta-analyses. Lancet. 1999;354(9193):1896-900

11. Liu M, Li L, He Y, Peng D, Wang X, Chen W, et al. Comparison of laparoscopy and laparotomy in the surgical management of early-stage ovarian cancer. Int J Gynecol Cancer. 2014;24(2):352-7.

12. Lee M, Kim SW, Paek J, Lee SH, Yim GW, Kim JH, et al. Comparisons of surgical outcomes, complications, and costs between laparotomy and laparoscopy in early-stage ovarian cancer. Int J Gynecol Cancer. 2011;21(2):251-6.

13. Koo YJ, Kim JE, Kim YH, Hahn HS, Lee IH, Kim TJ, et al. Comparison of laparoscopy and laparotomy for the management of early-stage ovarian cancer: surgical and oncological outcomes. J Gynecol Oncol. 2014;25(2):111-7.

14. Park JY, Kim DY, Suh DS, Kim JH, Kim YM, Kim YT, et al. Comparison of laparoscopy and laparotomy in surgical staging of early-stage ovarian and fallopian tubal cancer. Ann Surg Oncol. 2008;15(7):2012-9.

15. Park JY, Bae J, Lim MC, Lim SY, Seo SS, Kang S, et al. Laparoscopic and laparotomic staging in stage I epithelial ovarian cancer: a comparison of feasibility and safety. Int J Gynecol Cancer. 2008;18(6):1202-9.

16. Lecuru F, Desfeux P, Camatte S, Bissery A, Blanc B, Querleu D. Impact of initial surgical access on staging and survival of patients with stage I ovarian cancer. Int J Gynecol Cancer. 2006;16(1):87-94.

17. Chi DS, Abu-Rustum NR, Sonoda Y, Ivy J, Rhee E, Moore K, et al. The safety and efficacy of laparoscopic surgical staging of apparent stage I ovarian and fallopian tube cancers. Am J Obstet Gynecol. 2005;192(5):1614-9.

18. Leblanc E, Querleu D, Narducci F, Occelli B, Papageorgiou T, Sonoda Y. Laparoscopic restaging of early stage invasive adnexal tumors: a 10-year experience. Gynecol Oncol. 2004;94(3):624-9.

19. Manolitsas TP, Fowler JM. Role of laparoscopy in the management of the adnexal mass and staging of gynecologic cancers. Clin Obstet Gynecol. 2001;44(3):495-521.

20. Eltabbakh GH. Effect of surgeon's experience on the surgical outcome of laparoscopic surgery for women with endometrial cancer. Gynecol Oncol. 2000;78(1):58-61

21. Gemignani ML, Curtin JP, Zelmanovich J, Patel DA, Venkatraman E, Barakat RR. Laparoscopic-assisted vaginal hysterectomy for endometrial cancer: clinical outcomes and hospital charges. Gynecol Oncol. 1999;73(1):5-11.

22. Tozzi R, Kohler C, Ferrara A, Schneider A. Laparoscopic treatment of early ovarian cancer: surgical and survival outcomes. Gynecol Oncol. 2004;93(1):199-203.

23. Schreuder HW, Pattij TO, Zweemer RP, van Baal MW, Verheijen RH Increasing experience in laparoscopic staging of early ovarian cancer. Gynecol Surg. 2012;9(1):89-96.

24. Weber S, McCann CK, Boruta DM, Schorge JO, Growdon WB. Laparoscopic surgical staging of early ovarian cancer. Rev Obstet Gynecol. 2011;4(3-4):117-22.

25. Kuntz C, Wunsch A, Bay F, Windeler J, Glaser F, Herfarth C. Prospective randomized study of stress and immune response after laparoscopic vs conventional colonic resection. Surg Endosc. 1998;12(7):963-7.
26. Harmon GD, Senagore AJ, Kilbride MJ, Warzynski MJ. Interleukin-6 response to laparoscopic and open colectomy. Dis Colon Rectum. 1994;37(8):754-9.

27. Brune IB, Wilke W, Hensler T, Holzmann B, Siewert JR. Downregulation of T helper type 1 immune response and altered pro-inflammatory and anti-inflammatory $T$ cell cytokine balance following conventional but not laparoscopic surgery. Am J Surg. 1999;177(1):55-60

28. Gallotta V, Ghezzi F, Vizza E, Chiantera V, Ceccaroni M, Franchi M, et al. Laparoscopic staging of apparent early stage ovarian cancer: results of a large, retrospective, multi-institutional series. Gynecol Oncol. 2014;135(3):428-34.

\section{Submit your next manuscript to BioMed Central and take full advantage of:}

- Convenient online submission

- Thorough peer review

- No space constraints or color figure charges

- Immediate publication on acceptance

- Inclusion in PubMed, CAS, Scopus and Google Scholar

- Research which is freely available for redistribution 